\title{
Application and Analysis of Curtain Grouting in Seepage Prevention and Reinforcement of Masonry Dam
}

\author{
Yao Huiqin $^{1 *}$, Liu Dongmei ${ }^{2}$, Peng Chaofu ${ }^{3}$ \\ ${ }^{1}$ College of Hydraulic \& Environmental Engineering of China Three Gorges University, Yichang, china,443002; \\ 2. College of Civil \& Architectural Engineering of China Three Gorges University, Yichang, china,443002; \\ 3. Department of Campus Planning and Construction of China Three Gorges University, Yichang, china,443002
}

\begin{abstract}
At present, the number of masonry dam in China is still relatively large. Due to various reasons, many of the dam body appears aging, degradation and other phenomena, and leakage is one of the common problems. Now grouting technology is the main technical means of anti-seepage treatment. Curtain grouting technology has wide adaptability to strata. With the gradual improvement of grouting technology, it has been widely applied in engineering and water conservancy projects. In order to ensure the safety of the dam and improve the grouting effect, this paper summarizes the rules of anti-seepage treatment based on the actual grouting treatment methods, and provides technical guidance for the anti-seepage treatment of other similar masonry dams.
\end{abstract}

\section{Introduction}

Masonry dam is one of the important dam types in water conservancy projects, which has a long history. At present, there are more than 2000 stone-masonry dams with a dam height of $15 \mathrm{~m}$ or more in China. Most of these stone-masonry dams were built in the 1960s and 1970s. Due to the limitations of the technical and economic conditions at that time, now many stone-masonry dams still have been used found aging, degradation and other phenomena, which have caused serious leakage of the dam foundation or abutment of the dam, causing partial failure of the project and even endangering the safety of the project. We need to pay attention to that and find out the cause of leakage and take effective anti-seepage measures to deal with it.

Curtain grouting technology has always been one of the main measures for seepage prevention and reinforcement. This method uses equipment to hydraulically pour grout into the dam body and dam foundation to fill the leaks and gaps in the dam body and dam foundation. The grouting reinforcement forms an impervious body, which can further improve the bearing capacity and integrity of the dam can solve the safety problems in the operation of the reservoir to a certain extent. Moreover, curtain grouting technology has low application cost, high safety and high overall benefits. It has a certain effect on improving the quality of the project and the safety factor of reservoir operation. Therefore, it is used more in the reservoir reinforcement project.

Based on the case study of grouting reinforcement of a dam, this paper analyzes and studies the problems and characteristics of mortar-masonry leakage, and determines the technical scheme of reinforcing grouting of dam body and curtain grouting of dam foundation after a comparison of two technical schemes. Through grouting technology treatment, the leakage problem of the dam is solved and the sliding stability safety coefficient of the dam is improved by increasing the bulk density of the dam body grouting and masonry, which basically eliminates the safety hidden danger of the original ailing reservoir dam and gives better play to the project benefits. The relevant design theory and construction points are improved to provide reference and basis for similar problems in the application of water conservancy projects in the future.

\section{Project overview}

The river in which the reservoir is located belongs to a branch of Yuanjiang river system in the Yangtze River Basin. The main buildings include masonry gravity arch dam, discharge bottom hole, discharge culvert and overflow surface hole. The dam is a grout masonry gravity arch dam with a maximum height of $16.6 \mathrm{~m}$. The masonry material of the dam body is grout

block stone, and the dam shell is grout stone. The dam overflowed in the middle.

The lithology involved in the strata on both sides of the reservoir area is the lower Cambrian Feilang Formation $(\in 1 \mathrm{p})$ gray, gray-green calcareous shale with siltstone, which is a non-soluble rock type and is a relatively water-resistant rock. The base of the dam is the Cambrian Middle Loquat Formation $(\in 2 p)$ : the lithology is gray, gray-green calcareous shale, the foundation is excavated to the middle weathered shale, and local sections are strongly weathered, and the quality of the 
dam foundation is good. There is no low adjacent valley lower than the normal water level of the reservoir on both banks of the reservoir area. The bedrock on both sides of the reservoir is composed of shale insoluble rock, and the lithological sealing condition is good.

The dam was built in 1981 as a mortar-masonry gravity arch dam. The maximum dam height is $16.6 \mathrm{~m}$. The dam shell is mortar limestone and the dam body is mortar-masonry. Then the front and back of the dam were mortar masonry stones with a width of about $0.5 \mathrm{~m}$, with concrete buried stones in the middle. When the water level of the dam is high, there will be flowing water on the downstream dam surface, and the masonry quality of the dam body is general. Up to now, the overall construction quality of the project is good, but there are leakage problems in the dam body, foundation and abutment.

\section{Anti-seepage reinforcement scheme}

\subsection{Current situation of leakage}

The dam has been in operation for nearly 40 years, and the mortar is of good quality and dense filling. No honeycomb, aging, weathering or peeling phenomenon has been observed in the mortar strips between the stone cracks of the dam body. There are phenomena of soaking, wetting, and dripping water on the downstream surface of the dam. On the downstream surface of the dam, there can be seen calcium deposits and cements produced by the seepage of the dam body, as well as mixed cements of the calcium cement and the discarded ballast rubble during the construction of the dam. At the same time, the dam body and the contact zone of the dam abutment have leakage problems, and the leakage amount is about 1 to $5 \mathrm{~L} / \mathrm{S}$. The overall construction quality of the project is good, and there are mainly the problems of scouring pits downstream of the dam foundation and leakage of the dam foundation.

The dam site area involves calcareous shale and siltstone, whose rock mass has low scour ability. Therefore, a scour pit is formed in the downstream reach of the dam foundation under the influence of long-term scour of overflow reservoir water at the dam top. The scour pit bottom elevation is about $446.67 \mathrm{~m}$, which is $0.58 \mathrm{~m}$ lower than the dam foundation elevation of $447.27 \mathrm{~m}$. Its existence has a negative impact on the anti-sliding stability of the dam. Therefore, it is suggested to backfill and seal the scour pit.

According to the survey, when the foundation surface of the dam was cleared, the strongly weathered broken rock mass had been removed. The dam foundation was placed on the weakly weathered rock mass, which was relatively complete. Due to the limitation of the construction conditions at that time, the dam foundation could not be treated with anti-seepage curtain grouting after the completion of the dam. Therefore, after the completion of the dam, there are different degrees of reservoir water leakage problems along the contact zone between the dam body and the foundation. Under the influence of long-term leakage of the reservoir water along the contact zone between the dam body and the dam foundation, the seepage water will infiltrate and soften the dam foundation rock mass, and may further reduce the shear strength index of the dam foundation rock mass, which has a negative impact on the anti-sliding stability of the dam body, and is detrimental to the safe operation of the dam.Therefore, it is recommended that engineering treatment measures such as anti-seepage curtain grouting should be taken for the dam foundation.

\subsection{Comparison and selection of anti-seepage schemes}

According to the leakage status of dam body and foundation (shoulder) and considering the construction conditions, two anti-seepage schemes are formulated for the dam body:

Scheme 1: The impervious body is installed on the upstream dam surface of the dam body. Reinforced concrete panels are adopted for impervious surface. Grouting platform is set at the foot of the upstream dam to carry out curtain grouting on the dam foundation. The upstream water level of this project can be lowered to the dead water level by the sand flushing hole at the bottom of the dam, but due to the reservoir running for many years, there is a certain amount of siltation at the foot of the dam upstream, so the upstream dam foot must be excavated to the foundation surface, and the concrete platform should be poured to carry out the curtain grouting seepage prevention of the upstream dam foundation. At the same time, the upper reaches of the dam are impervious with reinforced concrete slabs, so the dam body and foundation will form a closed impervious whole and the impervious effect is better. However, the construction technology of this scheme is more complicated, the construction layout is more difficult. It is difficult to control water flow during the construction period.

Scheme 2: The impermeable body is installed in the dam body. The dam body after the demolition of the overflow surface is drilled, and the dam body can be reinforced grouting. The curtain grouting is carried out on the dam foundation, and the part above the dead water level on the upstream surface of the dam body is jointed.

The dam is a gravity arch dam with a thickness of $1.1 \mathrm{~m}$ to $4.14 \mathrm{~m}$. Grouting holes can be arranged on the working face after the demolition of the overflow surface. The width of the top of the dam after the demolition is about $3.25 \mathrm{~m}$. It is proposed to install curtain grouting holes in the dam body, and carry out reinforcement grouting for the dam body and vertical grouting for the dam foundation to prevent seepage.

The comparison of specific anti-seepage schemes is shown on table 1 . 
Table 1 Comparison of Anti-seepage Schemes

\begin{tabular}{|c|c|c|}
\hline Scheme & Scheme 1 & Scheme 2 \\
\hline Content & $\begin{array}{l}\text { The upstream } \\
\text { cofferdam is } \\
\text { constructed, and the } \\
\text { foot of the dam is } \\
\text { excavated to the } \\
\text { bedrock. The pouring } \\
\text { concrete platform can } \\
\text { be used as the } \\
\text { grouting construction } \\
\text { platform. ho The } \\
\text { grouting holes are } \\
\text { arranged in single row } \\
\text { with a distance of } \\
\text { 2.0m. Inserting } \\
\text { reinforcement is } \\
\text { implanted on the } \\
\text { upstream surface of } \\
\text { the dam and poured } \\
\text { reinforced concrete } \\
\text { panel for seepage } \\
\text { prevention, with a } \\
\text { thickness of 20cm. }\end{array}$ & $\begin{array}{l}\text { The original jointing } \\
\text { cement on the } \\
\text { upstream surface of the } \\
\text { dam can be removed, } \\
\text { and high-grade cement } \\
\text { mortar can be used to } \\
\text { re-join the joint. Using } \\
\text { the top of the dam as a } \\
\text { construction platform } \\
\text { after the overflow } \\
\text { surface is removed, the } \\
\text { dam body can be } \\
\text { carried out } \\
\text { reinforcement grouting } \\
\text { and he dam foundation } \\
\text { can be carried out } \\
\text { curtain grouting. The } \\
\text { grouting holes are } \\
\text { arranged in a single } \\
\text { row with a space of } \\
2.0 \mathrm{~m} \text {. }\end{array}$ \\
\hline $\begin{array}{l}\text { Advanta } \\
\text { ges }\end{array}$ & $\begin{array}{l}\text { Anti-seepage form a } \\
\text { closed body, with } \\
\text { better anti-seepage } \\
\text { effect. }\end{array}$ & $\begin{array}{l}\text { The construction } \\
\text { technology is mature } \\
\text { and simple, with good } \\
\text { anti-seepage effect. }\end{array}$ \\
\hline $\begin{array}{l}\text { Disadva } \\
\text { ntages }\end{array}$ & $\begin{array}{l}\text { The construction } \\
\text { process is } \\
\text { complicated, so the } \\
\text { upstream surface of } \\
\text { the dam must be } \\
\text { chipped and cleaned. } \\
\text { The expansion } \\
\text { coefficient of the } \\
\text { concrete and the dam } \\
\text { is different, therefore, } \\
\text { cracks are easy to } \\
\text { appear. }\end{array}$ & $\begin{array}{l}\text { A construction } \\
\text { platform should be } \\
\text { built at the top of the } \\
\text { dam and the grouting } \\
\text { pressure must be } \\
\text { determined according } \\
\text { to the pressurized } \\
\text { water test. }\end{array}$ \\
\hline $\begin{array}{l}\text { Compar } \\
\text { ing } \\
\text { results }\end{array}$ & \multicolumn{2}{|c|}{$\begin{array}{l}\text { According to the comprehensive comparison, } \\
\text { the second option is finally selected as the } \\
\text { recommended implementation plan. }\end{array}$} \\
\hline
\end{tabular}

\subsection{Initial design of seepage control scope}

It is proposed to implement curtain grouting for sections where the seepage channels and permeability coefficient of the dam body, foundation and abutment on both sides of the dam can't meet the requirements of the standard until the relatively weak boundary of permeable layer is closed with the boundary of impervious curtain top, forming a complete scope of impervious system.

The impervious curtain line of this dam is arranged along the axis of the dam top, with a single row of holes with a distance of $2.0 \mathrm{~m}$. The grouting boundary of the left and right bank extends $3 \sim 6 \mathrm{~m}$ at the intersection of the normal water level and the underground water level. The lower boundary is the rock layer with $\mathrm{q}<10 \mathrm{Lu}$ extended by the curtain hole at the foundation of the dam.

For the F1 fault on the left bank of the dam, dense grouting is used for the construction of impervious curtain. The curtain grouting of the section
$\mathrm{W} 0+06.0 \mathrm{~m} \sim \mathrm{W} 0+19.2 \mathrm{~m}$ axis pile is set with a single row of holes, and the spacing of the holes is $1.0 \mathrm{~m}$.

\section{Curtain grouting project}

\subsection{Design parameters and standards of curtain}

\section{grouting}

The curtain grouting of dam foundation surface adopts cement slurry grouting, which is carried out by three sequence holes.

The curtain design adopts a single row of holes with a distance of $2.0 \mathrm{~m}$. The rock penetration depth is $5 \mathrm{~m}$. The construction is divided into three sequence holes. First, the first sequence hole is used as the grouting pilot hole. The upper limit of grouting is subject to the design starting height. Firstly, pilot hole construction is carried out. Through pilot holes, the physical and mechanical properties of the bedrock, cracks, karst, pore water pressure, and the amount of grouting per grouting section are initially determined, so as to optimize the grouting design and adjust the bottom limit of the grouting hole for grouting construction, which can provide necessary data for grouting construction. The standard for seepage prevention is that the rock permeability is not more than $10 \mathrm{Lu}$.

\subsection{Construction process of curtain grouting}

The grouting construction shall execute the "Technical Code for Cement Grouting Construction of Hydraulic Buildings" (SL62-94) and related materials and documents. The grouting shall be carried out on pilot hole or test data as the basis for holes layout. The pilot hole must be subjected to water pressure test during construction, and adjusted or optimized according to the water pressure test data with the approval of the design department.

The grouting method adopts the top-down circulation type, and the contact section between the dam body and the bedrock must be grouted separately. The boreholes shall be drilled to $1 \mathrm{~m}$ below the bedrock surface, and the contact sections of $1 \mathrm{~m}$ above and $1 \mathrm{~m}$ below the bedrock shall be used for grouting. The number of inspection holes is $10 \%$ of the number of drilled holes, and the depth of hole exceeds the maximum depth of the two adjacent holes by $2 \mathrm{~m}$. Grouting shall be backfilled after the completion of inspection.

The grouting is carried out in a three-sequence stepwise densification method. First the I sequence hole is drilled and grouted, then the II sequence hole is drilled and grouted, and finally the III sequence hole is drilled and grouted. The bedrock is grouted in sections from top to bottom, and the grouting plug should be plugged below $0.5 \mathrm{~m}$ from the top of the filled section to prevent leakage. It is necessary to wait a certain period of time after grouting for each section to ensure the quality of grouting.

Rotary drill shall be used for drilling holes, and the 
deviation between the drilling position and the design position should not be greater than $10 \mathrm{~cm}$. The construction procedure of curtain grouting hole should be carried out in accordance with the principle of first thin and then dense grouting, and the construction should be carried out strictly in accordance with the sequence of grouting holes.

Each section of grouting hole must be flushed before grouting to ensure smooth fracture and good cementation between slurry stone and rock mass. After the washing is finished, grouting shall be carried out immediately. In the process of hole making, the I sequence grouting hole should be tested by water injection. The bedrock hole section is subjected to a water pressure test to understand the development of cracks in the dam body and rock mass, which can provide selection of curtain depth, cement consumption and water-cement ratio for grouting and conduct a comprehensive analysis with each hole that has been poured.

According to the relevant regulations of impermeable curtain grouting, the strength of $\mathrm{P} \cdot \mathrm{O} \cdot 42.5$ ordinary Portland cement is used for curtain grouting cement in order to ensure the grouting quality. The length of grouting section is $2 \sim 3 \mathrm{~m}$, which can be extended under special circumstances. In the contact zone between the bedrock and the overburden, the drilling should be stopped for grouting after entering the bedrock $2 \mathrm{~m}$. According to the engineering conditions, the grouting pressure is determined as follows: the grouting pressure in the bedrock adopts $1.5 \sim 2$ times of the water pressure, and the allowable grouting pressure in the first section is $0.4 \mathrm{Mpa}$. The pressure increases by $0.02 \mathrm{mpa}$ when the depth increases by $1 \mathrm{~m}$. At the beginning of the grouting, the pressure should be increased to rule as soon as possible. Under the prescribed pressure, the slurry mixture ratio should be changed and the concentration should be increased step by step after the cumulative slurry absorption of each level of concentration slurry reaches a certain limit. As the slurry concentration increase step by step, the cracks are filled gradually, and the absorption slurry unit will decrease gradually, until the end standard is reached, namely the end grouting. When the foundation water permeability is serious and the amount of slurry absorption is large, the step-up grouting method is adopted. In the construction process, two grouting points should be selected for test grouting to observe the changes in the whole process and the pressure value should be adjusted. The pressure value determined after the adjustment should ensure the construction quality. The slurry concentration should be changed step by step from thin to thick. Completion standard of grouting is based on the specification. When top-down grouting is adopted, if the injection rate is greater than $0.4 \mathrm{~L} / \mathrm{min}$, perfusion continues for $60 \mathrm{~min}$. If it is not greater than $1 \mathrm{~L} / \mathrm{min}$, perfusion continues for 90 minutes to finish the grouting. All qualified grouting holes can be sealed after careful inspection. The sealing material can be M20 cement mortar. The mixing amount of sand can be $1 \sim 2$ times of cement, and the grouting temperature should be within $0 \sim 40^{\circ} \mathrm{C}$. When curtain grouting adopts the top-down segmented grouting method, the grouting hole should be sealed by "segmented grouting method" or "full-hole grouting method".

\subsection{Analysis of curtain grouting quality}

After grouting, 10\% inspection holes shall be arranged. The drilling and water pressure test of inspection holes shall be carried out 14 days after the completion of the grouting. The water pressure (or water injection) test should be carried out in sections from top to bottom and adopt the five-point method. The diameter of inspection hole should be greater than or equal to $76 \mathrm{~mm}$, and the core recovery rate should be up to $80 \%$. The depth maximum of two adjacent holes is $2.0 \mathrm{~m}$. The inspection hole should be used to check the grouting effect, which should be $5 \mathrm{~m}$ deeper than the grouting hole. The position of inspection hole can be arranged in the section with poor grouting quality or good geological conditions.

The inspection content is mainly to check whether the unit water absorption is less than $10 \mathrm{Lu}$ through the pressure test. If the unit water absorption is less than $10 \mathrm{Lu}$, it is considered that the curtain seepage prevention meets the requirements. The pass rate of the contact section between the dam and the bedrock and the next section should be $100 \%$. The pass rate of the following sections should be above $90 \%$, then the grouting quality can be qualified. It has been proved that the curtain grouting has played a very good anti-seepage effect in the reinforcement projects of multiple reservoirs.

\subsection{Treatment of grouting problems}

(1) In the process of grouting, riser, leakage and other situations can be found and should be treated by methods such as joint, surface sealing, low pressure, concentrated grouting, current limiting and intermittent grouting according to the specific situation. It is found that grouting can be carried out at the same time if the grouting holes are equipped with grouting conditions. One pump and one hole should be used. Otherwise, the grouting holes should be plugged. After the grouting is finished, the grouting holes should be cleaned and flushed again, then we can continue drilling and grouting.

(2) When the grouting is difficult to be finished due to the large amount of injection in the grouting section, some measures can be used, such as low pressure, concentrated grouting, current limiting, intermittent grouting, mixing of accelerating agent in the grout, and filling of stable grout or mixed grout. After the treatment of this section, the holes should be cleaned and the grouting should be carried out again according to the technical requirements until the grouting is finished.

(3) In case of grouting in karst caves, it is necessary to find out the dense physical type and scale of karst caves and conduct connectivity test before taking corresponding measures to deal with them.

(1) If there is no dense material in the cave, according to the size of the cave, it can be used to pump into high-flow concrete, put in gravel reperfusion cement 
mortar, mixed slurry and other measures. The hole should be cleaned and can be poured cement slurry after setting.

(2) When there are dense material inside the cave, high-pressure grouting and high-pressure jet grouting can be adopted according to the type, performance and degree of compaction of the dense objects. When the injection volume is large, the previous method can be used.

(3) If grouting stops suddenly for some reason and cannot be resumed for a while, the grouting hole should be washed with clean water and then refilled.

\section{Conclusion}

There are still a large number of masonry dams in the world. With the rapid development of materials and technology and the gradual improvement of environmental protection requirements, new masonry dam will be less and less. However, it is still a problem we need to face that how to deal with the old renovation and reinforcement of the old and dangerous masonry dams to make them better and play more benefits. The problem of leakage is a common problem of mortar-masonry dams. At present, grouting technology is still the main technical means of anti-seepage treatment. The curtain grouting technology has a wide adaptability to the stratum. With the gradual improvement of grouting technology, it has been widely used in engineering, especially in water conservancy and reinforcement projects. In order to ensure the safety of the dam and improve the grouting effect, this paper summarizes the anti-seepage treatment rules in combination with the grouting treatment method of the actual project, which can provide technical guidance for the anti-seepage treatment of other similar dams.

\section{Acknowledgments}

This paper is one of the phased achievements of "The study on the durability and life prediction of impervious curtain of gravity dam under service environment" Research (51809153), a general project of the National Natural Science Foundation of China.

\section{Reference}

1. ZHANG Jingxiu, (2002) Seepage Prevention of Dam Foundation and Grouting Technology. China Hydropower Publishing Company, Beijing.

2. DL/T 5148-2001, Technical Code for Cement Grouting Construction of Hydraulic Structures.

3. TAN Deyuan, (2007) Application of anti-seepage treatment design in reservoir reinforcement project[J]. China Rural Water and Hydropower, 7: $118 \sim-120$.

4. Johnse, Kenneth S. (2008) Gypsum-karst Problems in Constructing Dams in the USA[J]. Environmental Geology, Special I-ssue Evaporite-Karst Processes, Landforms and Environmental Problems.5:945
950

5. Hiroshi Saitoa, Akira Deguchi, (2000) Leaching tests on different mortars using accelerated electrochemical method. Cement and Concrete Research, 30:1815 1825 